\title{
The Impact of Black Swan Events on Stock Prices: Evidence from the Melamine Incident in China
}

\author{
Wenjian ZHU \\ University of Queensland, Business Economic and Law Faculty, Brisbane, Australia
}

\begin{abstract}
The influence of melamine incident on dairy industry in 2008 was investigated, and the control effect of different enterprises on the black swan incident was analyzed. First of all, this paper analyzes the impact of the stock of listed companies in the dairy industry after the black swan incident, and compares the impact of the different risk treatment of several leading enterprises on the stock price recovery.

The results show that: first, the melamine incident has a negative effect on the enterprises involved, and the enterprises involved do not have a competitive advantage. Second, in the same period, enterprises pay more attention to the influence of black swan event and take more powerful measures. The greater the risk treatment intensity is, the less the influence of black swan event will be. Third, the two enterprises have similar risk handling strength. The faster the response to risk events, the earlier the processing time, and the less affected by the black swan event.
\end{abstract}

\section{Introduction}

In recent years, food safety problems have emerged endlessly. Cases of production and sale of shoddy, poisonous and harmful foods have been publicly exposed, with thousands of victims. This issue has become the focus of attention. Because it is not only related to the physical health and life safety of the broad masses of people, but also to the healthy economic development and social stability. For food safety incidents, what often appear in the public eye are formaldehyde beer, "hanging white blocks" in tofu, excessive bacteria in Evian mineral water, canned melon luncheon meat residue, "Sudan red" duck eggs, etc. The food safety incident selected for this study is the "melamine" incident. On the one hand, the melamine poisoning milk powder incident has a great impact and is worth studying. In addition, compared with other food safety issues, the problems of infant milk products have attracted more attention and have more research value. Because even the public who joked that they are not poisonous, they will pay more attention to the food quality problems that endanger young children. Therefore, it is more realistic and representative to study food safety cases in the dairy industry. On the other hand, the companies involved in the melamine incident have high homogeneity, which is conducive to reducing the influence of irrelevant factors and making relevant experiments more accurately.

After the Black Swan incident, such negative information affected the company's image and reputation, and caused heavy losses in the domestic dairy industry.
According to the 2008 financial report, the active largescale dairy companies (Yili Shares, Bright Dairy, Sanyuan, Mengniu Dairy) In addition to the slight profit of Sanyuan, the remaining three dairy companies have lost more than 3 billion yuan. At the same time, the incident caused investors to have a distrust of the stocks of the companies involved, which is reflected in the fluctuations in the stock prices of the companies. If a more effective response strategy can be adopted to make the public see the company's responsible attitude when facing negative events, investors' confidence in the company will slowly recover. Therefore, as time goes by, the negative impact on the Black Swan incident is gradually diminishing, and the company's stock will gradually rise. In this recovery process, due to different risk management strategies and directions adopted by different enterprises, the recovery time will vary. The picture below shows the impact of the Black Swan incident on the stock price and the recovery process of the stock price after taking measures to control the negative evaluation.

\section{LITERATURE REVIEW}

\subsection{Proposal and Application of Event Research Method}

First, the research method used in this paper is event study, which was proposed by Fama (1969) ${ }^{[15]}$. Based on the premise of an efficient market: rational investors can rationally respond to new information, stock prices can 
reflect all known public information, and the occurrence of a particular event will cause changes in stock prices. This research method uses stock price changes to reflect market information. By observing changes in the stock price of a selected sample before and after a particular event, it can be investigated whether the occurrence of a particular event will cause abnormal stock price returns. In many articles analyzing black swan events and negative events, many people use the event analysis method to analyze, such as Zhang and Zhang $(2018)^{[1]}$, Liu and Meng (2016) ${ }^{[2]}$ and others also use the event research method to test the company's negative events Market response. In general, analyzing the negative impact of corporate risk events generally uses event analysis, which can help us analyze the short-term impact of negative information on the company.

\subsection{Relationship between Black Swan Incident and Stock Price}

The Black Swan incident generally has a negative impact on the stocks involved, and will not have a negative impact on companies that are not involved.

For example, Zhan and $\mathrm{Wu}(2012)^{[3]}$ studied the impact of the stock price on the airliner crash as a black swan incident, and found that after the aircraft accident, the stock price of the crashed aircraft company immediately fell, while other stock prices in the industry have risen. On the black swan incident related to food safety issues, Zhang et al. (2010) ${ }^{[4]}$ studied the impact of melamine toxic milk powder incident on the stock return of China's dairy industry based on the event research method. After analysis, it was concluded that it was affected by "melamine" The impact of the incident, the stock price fluctuations increased, and fell sharply.

\subsection{Relationship between Black Swan Incident Response and Stock Price}

In the face of the Black Swan incident, how to manage the resulting risks plays an important role in the survival and development of the company, and emphasized the need for timely risk control and crisis control. As mentioned by Lerbinger $(1997)^{[14]}$, when a risk event occurs, it is extremely rapid and sudden. If the company does not take relevant actions, the problem will quickly develop in a worse direction and cannot be recovered.

At the same time, the company's response to the Black Swan incident has a certain relationship with the stock price. Song (2017) ${ }^{[6]}$ proposed that companies need to bear their own social responsibilities, showing that this helps to form the information effect and reputation insurance effect, and to a certain extent, mitigate the risk of a sharp decline in stock prices. Tian et al. $(2018)^{[7]}$ also mentioned that public opinion must pay attention to timely response to negative events, and companies with better response have a lower risk of a sharp decline in their stock prices when facing negative events, so listed companies strengthened their response to negative events. The response and control of public opinion is a very necessary measure for the management of stock price fluctuations.

Generally speaking, the existing literature mainly analyzes the effects of negative events on the stock price. Generally, the incidents involved have negative effects and will not have significant negative impacts on the companies that are not involved. In terms of responding to negative events, the existing literature does not specifically analyze the effects of coping strategies and strength on adverse effects and the effect of stock price recovery. Therefore, after analyzing the negative impacts on the companies involved, this article will continue to analyze crisis management. The impact of measures, efforts and other aspects on stock price recovery.

\section{3 data and research method}

\subsection{Event study setting}

We use a standard event study approach to assess the effect of the 2008 milk/melamine scandal on dairy stocks returns and the tendency of price changes. The main steps involved in the setting are: event identification (event timing, estimation and event window identification), sample identification (sample stocks and control stocks), measuring normal stock returns and abnormal returns, statistical testing, and empirical result analysis. Subsequent analyses are also conducted following this procedure.

\subsubsection{Event timing}

The milk/melamine scandal took place in July 2008, following reports of an abnormal increase in incidents of kidney ailments among infants after consuming baby formula produced by Sanlu. As these incidents attracted widespread attention from the public, on September 11th the Chinese Ministry of Health issued a warning that dairy products produced by Sanlu were contaminated and consumption must be ceased. On September 14th the General Administration of Quality Supervision, Inspection and Quarantine (AQSIQ) held an emergency meeting, and issued a directive mandating a thorough investigation of all dairy companies and dairy products, where questionable companies must cease production. On September 16th a number of dairy companies, including listed companies such as Yili, Mengniu and Bright (Bright Food (Group) Co., Ltd.), were revealed to have produced and sold melamine contaminated dairy products. These dairy company stock prices quickly fell afterwards. 
Table 1 Major event timeline

\begin{tabular}{|c|c|c|c|}
\hline & Date & Event & Description \\
\hline 1 & September $11^{\text {th }}$ & $\begin{array}{l}\text { Milk products manufactured by } \\
\text { Sanlu were found to be } \\
\text { contaminated by melamine. }\end{array}$ & $\begin{array}{l}14 \text { infants in Gansu province were } \\
\text { reported to have become ill due to } \\
\text { kidney ailments, and all have consum } \\
\text { milk products manufactured by Sanll }\end{array}$ \\
\hline 2 & September $13^{\text {th }}$ & $\begin{array}{l}\text { Major food safety alert Level I } \\
\text { activated. }\end{array}$ & $\begin{array}{l}\text { Major food safety alert Level I activa } \\
\text { by the central government, as a resp } \\
\text { to the melamine incident. }\end{array}$ \\
\hline 3 & September $14^{\text {th }}$ & AQSIQ initiated investigation. & $\begin{array}{l}\text { AQSIQ instructed local authorities to } \\
\text { conduct investigation on related dairy } \\
\text { companies, and ordered questionable } \\
\text { companies to cease production. }\end{array}$ \\
\hline 4 & September $16^{\text {th }}$ & $\begin{array}{l}\text { Milk products manufactured by Yili, } \\
\text { Bright and Mengniu were found to } \\
\text { be contaminated by melamine. }\end{array}$ & $\begin{array}{l}\text { Investigations revealed dairy product } \\
\text { manufactured by Yili, Bright, Mengni } \\
\text { and other } 19 \text { companies were } \\
\text { contaminated by melamine, causing } \\
\text { great uproar. }\end{array}$ \\
\hline
\end{tabular}

\subsubsection{Estimation and Event Window Identification}

We use the first trading day following the public revelation of the milk/melamine scandal (September 16th, 2008) as the event date: September 17th, 2008 $(\mathrm{t}=0)$. Market model estimation is based on a 150-trading day estimation window ending 15 days preceding the event date $(\mathrm{t}=-165$ to $\mathrm{t}=-15)$, with the trading day on September 17th, 2008 designated as $\mathrm{t}=0$, while the event window being $t=-15$ to $t=+15$. The estimation and event windows are used to calculate abnormal returns and cumulative abnormal returns for involved dairy companies.

\subsection{Data}

\subsubsection{Sample selection}

Our sample comprises affected dairy companies in the $2008 \mathrm{milk} / \mathrm{melamine}$ scandal, and were listed before the incident. Initial sample firms in the broader food industry were identified and collected from the Tonghuashun software and the China Stock Market \& Accounting Research Database (CSMAR), and were filtered by whether the initial sample firms engage in dairy products in their respective main business line. As the milk/melamine scandal is mainly a food safety incident in the dairy industry, in order to have homogeneous samples, we select dairy producers specializing in traditional dairy products, including consumer milk drinks and baby formula products.

Table 2 Sample firm selection

\begin{tabular}{|c|c|c|}
\hline Company & Selected? & Reason \\
\hline Huang Shi & $\times$ & $\begin{array}{l}\text { Was not listed by the time of the incident, data } \\
\text { unavailable. }\end{array}$ \\
\hline Yili & $\sqrt{ }$ & $\begin{array}{l}\text { Listed before } 2008 \text {, products were found to be } \\
\text { contaminated by melamine. }\end{array}$ \\
\hline Beingmate & $\times$ & $\begin{array}{l}\text { Was not listed by the time of theincident, data } \\
\text { unavailable. }\end{array}$ \\
\hline Sanyuan & $\sqrt{ }$ & $\begin{array}{l}\text { Only has data available until stock ceased } \\
\text { trading on September } 26^{\text {th }}, 2008 \text { due to } \\
\text { Sanyuan's acquisition of Sanlu. Data available } \\
\text { after February } 16^{\text {th }}, 2009 \text { when trading } \\
\text { resumed. }\end{array}$ \\
\hline Bright & $\sqrt{ }$ & $\begin{array}{l}\text { Listed before } 2008 \text {, products were found to be } \\
\text { contaminated by melamine. }\end{array}$ \\
\hline Mengniu & $\sqrt{ }$ & $\begin{array}{l}\text { Listed on the Hong Kong Stock Exchange } \\
\text { since } 2004 \text {, products were found to be } \\
\text { contaminated by melamine during the incident. }\end{array}$ \\
\hline Sanlu & $\times$ & $\begin{array}{l}\text { Major culprit in the melamine incident, has } \\
\text { been insolvent after the incident. }\end{array}$ \\
\hline
\end{tabular}

Table 2 shows our sample firm selection process. We select Yili, Bright, Mengniu and Sanyuan as our sample firms. Firstly, while there were 22 firms involved in the incident, only Yili, Bright, Mengniu and Sanlu were 
listed entities, and Sanlu has gone bankrupt following the incident and was subsequently acquired by Sanyuan. Secondly, Yili, Bright, Mengniu and Sanyuan are the major players in the Chinese dairy market, and have homogenous firm characteristics. With a major food safety incident like the milk/melamine scandal, it is more appropriate to focus on these large players to give rise to public discussion and reflection. In addition, as listed entities, data availability (e.g., firm characteristics, financial data, stock data) in empirical analysis is a key consideration in selecting these four firms. Accordingly, our final sample consists of Yili, Bright and Mengniu as firms negatively affected by the incident, and Sanyuan as a control firm (Sanyuan was not directly involved in the incident as it was not subject to melamine contaminated products).

Firm and financial data were collected from the CSMAR database, China Listed Companies Information website (http://www.cnlist.com), Juchao database, and firms' quarterly and annual financial reports. We use adjusted daily stock returns and daily market returns to measure the stock market impact of the incident. Market returns are proxied by the Shanghai Stock Exchange Composite Index and the Hengseng Index. Both equally weighted market indices and value weighted indices are used as part of sensitivity analysis.

\subsubsection{Control sample}

In the $2008 \mathrm{milk} / \mathrm{melamine}$ scandal, Sanyuan has shown relatively sound competitive edge, and as such we use Sanyuan as our control firm in comparing the effect of the incident with the three negatively affected firms. Sanyuan's reaction to the incident can also be used as a baseline in measuring the impact on the other involved firms.

\subsection{Measuring predicted and abnormal returns}

The event study approach is usually conducted by analyzing abnormal stock returns, and the most popular way to do so is to measure cumulative abnormal returns (CARs). The basic idea is to quantify the difference between the predicted stock returns based on information prior to the event and assuming the particular event/incident has not occurred, and the actual stock returns after the event. If the event is not informationally relevant, the predicted returns should be very close to the actual returns. As such, a significant different between the predicted and actual returns, usually termed as abnormal returns (ARs), reflects the impact of the event on affected stocks.

Cumulative abnormal returns (CARs) are calculated by summing daily abnormal returns (ARs) over the event window and are used to measure the overall response of the stock market to a particular event. We use the market and risk-adjusted return model (i.e., the standard market model) to calculated predicted stock returns, as the market model is based on minimizing the variance of abnormal returns, and is therefore appropriate in determining the impact of black swan events.

\subsection{Testing for statistical significance}

In statistical tests, $\mathrm{t}$ tests are mainly used for statistical inference. Abnormal returns (ARs) and cumulative abnormal returns (CARs) are used to derive cumulative average abnormal returns (CAARs), and CAARs are subsequently tested for statistical significance. The null hypothesis is denoted as $\mathrm{H} 0$ and the alternative hypothesis denoted as $\mathrm{H}_{1}$.

\subsection{Measuring the effect of risky events}

When faced with risk, firms have differential responses, and are often characterized with heterogenous control magnitude and efficiency. In order to measure firms' efficiency in managing black swan events, we quantify the magnitude of enterprise crisis management so that firms' crisis management actions can be quantified and translated into crisis management costs.

As for the costs of crisis management, existing accounting standards do not require setting up a 'contingency profit and loss' item, and as such it is difficult to examine firms' true cost of crisis management expenditure. To overcome this, we use estimates derived from general and administrative expenses before and after the crisis event and other extraordinary expenses to analyze the costs associated with crisis management. During a food safety incident, firms usually engage in destroying defective products, make disclosure of relevant information, and conduct public relation maneuvers to contain the negative impacts resulting from the crisis. This kind of particular costs are usually classified as general and administrative expenses (e.g., Yili and Bright have both made disclosure in their financial reports that melamine incident related losses/costs were included in the general and administrative expenses item), and as such when measuring firms' crisis management magnitude, after removing seasonal/cyclical factors we can analyze the change in this particular expense item, to better compare the magnitude of crisis management across firms.

To compare the magnitude of crisis management between two firms, we compare each firm's quarterly general and administrative expenses with its previous year's quarterly amount, to derive an estimate of the growth rate of crisis management expenses: (change in current quarterly expense - previous year's quarterly expense) / previous year's quarterly expense.

\section{Results and discussion}

\subsection{Market reaction}

We compute the predicted stock returns using a 150 estimation trading-day period, and compute the corresponding ARs and CARs.

Fifteen trading days before the melamine incident, the four firms' CARs were all very close to 0 , and the lines overlap with each other. 
After the black swan event, however, there have been different movements in stock prices for Sanyuan as a non-involving firm in the incident. Sanyuan's stock price has gone down in day 2 and day 3, but afterwards has been climbing, showing great competitiveness (Sanyuan's CARs are all above 0 for a few days after September 17th, 2008).

For the other 3 involved firms - Yili, Bright and Mengniu, their CARs have been significantly affected since the incident. When the incident broke out in September 11th, as Sanlu was the only firm involved in the negative event on that day, Yili, Bright and Mengniu have gained some investor confidence/trust in that their products were not contaminated, and as such these 3 firms' stock prices have shown some degree of competitive effect, being similar to each other and were all above 0 (for example, on September 12th, 14th, and 16th, Yili's CARs are 0.0551, 0.0444, and 0.0286, respectively). However, since September 16th, Yili, Bright and Mengniu were all identified officially to have produced and sold products contaminated by melamine, and their stock prices started to fluctuate the next day, and their CARs have also shown various levels of decline, especially for Mengniu, whose CAR has shown significant decline three days after the incident broke out.

Although all three firms' CARs were subject to increased volatility, they experienced different levels of decline. For Bright, it experienced slight decline followed by gradual increase. At $\mathrm{t}=3$, Bright's CAR showed apparent decline at -0.3245 , and bounced back afterwards, stabilized at -0.2 , which is comparatively minor compared to the other two affected firms. Mengniu's stock price didn't show significant change on September 16th, but experienced large decline 3 days after, with a decrease in CAR at $-0.8827(\mathrm{t}=4)$. This is a large negative change in stock return, reflecting the significantly negative impact the black swan event has brought to Mengniu. In addition, according to data from the Wind database, Mengniu has been making large profits before the melamine incident. The firm has seen net profit growth rates of $94 \%, 43 \%, 59 \%$, and $29 \%$ between 2004 and 2007. Mengniu experienced its first net loss since the incident, according to Mengniu's 2008 financial reports, its net loss for the year was around RMB950 million. Yili also experienced large decline in CAR, but not as severe as Mengniu.

The significant declines in CARs for the three involved firms indicate the negative reception by the general public following the melamine incident, and the incident has also brought about severe negative influence. Investors significantly downward adjusted the three firms' stock prices, and consumers have shown loss of trust in the three firms. These can be verified from the sharp decrease in profits from the three firms' annual reports for Q3 2008.

\subsection{Empirical results}

We conduct $t$ tests to test for the effect of the melamine incident on the involved firms' stock returns. The result shows that the CARRs during the event window (31 trading days) are significant and thus verifies the cumulative abnormal returns following the incident.

While all three firms were subject to the negative impact of the incident, they suffered different levels of stock price declines. This shows that for the same black swan event, different firms have different responses and crisis management approaches. This is consistent with our prior belief that risk management practice makes a difference in the degree of stock price impact. As such, we continue to explore the effect of risk management on stock prices.

Table 3 T test on CAAR

\begin{tabular}{|c|c|c|c|}
\hline t-statistics & degrees of freedom & significance & average difference \\
\hline-4.897 & 30 & 0 & -0.20973 \\
\hline sample size & average & standard deviation & average standard error \\
\hline 31 & -0.2097 & 0.23845 & 0.04283 \\
\hline
\end{tabular}

\section{5 effect of risk management on stock prices}

The CARs of the three involved firms are very different from each other. All being stocks negatively involved in the melamine incident, Bright's CARs are comparatively larger than those of Yili and Mengniu, indicating that the negative effect due to the incident is less severe for Bright, compared to Yili and Mengniu. We examine firms' risk management strategy, management magnitude, and timing of response, to explore why Bright was less severely affected than the other two involved firms.

\subsection{Firms' risk management strategy}

All three involved firms have conducted corresponding actions following the black swan event, in order to mitigate/contain the crisis effect.

\subsubsection{Yili}

Yili took prompt actions when the incident broke out by dealing with the various problems associated with the crisis, to prevent the crisis to become even more severe. Some measures taken by Yili were effective while others not so (Yili took some preventative measures in the early stage following the incident but wasn't able to achieve 
its desired effect). The movement in Yili stock prices between 40 days preceding the incident (July 22nd, 2008) to August 27th, 2009 (by which time Yili's stock price has roughly returned to its pre-incident level). For around one year, Yili's stock price reverted back to its normal level before the black swan event.

\subsubsection{Disclosure of false information}

On September 17th, Yili made a public announcement that at an early stage the company has recalled its melamine-contaminated products from the market, and the company would recall any contaminated products from end-consumers, and the company apologized for the food safety incident. The management at Yili also vouched that they will ensure the quality and safety of their products, and gave relevant measures aimed to deal with incident. In addition, one day after the incident broke out, Yili claimed that all its products have passed tests conducted by the Ministry of Health, and were found safe. However, a detailed investigation on September 18th revealed that some of Yili's products were contaminated by melamine, and on the same day, some of Yili's honor designations were retracted.

It can be seen form the stock price reactions of Yili, that one day after the incident broke out, Yili's stock price has declined from RMB13.69 to 12.09, a drop of $11.69 \%$. When the company was found out making false statements about its products' safety, the decline in stock prices was significantly larger. Until September 22nd, for only two trading days, Yili's stock price plummeted to RMB9.99.

\subsubsection{Letter of apology}

To address the melamine incident, on September 18th Yili has issued a letter of apology "to dear mothers from the Yili Group". While being a letter of apology, the content of letter however emphasized that although Yili's products contained melamine and it was a breach of food safety standard, these products would not cause harm to consumers; and also because a lot of the company's products were targeted at children above 3 years old but not infants, so it was relatively safer. Compared to some other involved dairy companies, Yili's apology showed lack of sincerity and shirking of responsibility. As such, Yili's stock price continued to decline after September $18^{\text {th }}$.

\subsubsection{Reliable baby formula safety month}

On November 1st, 2008, Yili initiated its "reliable baby formula safety month" activity. This initiative was in collaboration with a number of other parties, including local health authorities and the media. By showcasing its production process via photos and videos, the initiative aimed at letting consumers informed of Yili's products and how they are manufactured, in an effort to have confidence in the company. This initiative was conducted in more than 30 cities around China, all with media coverage, and resulted in positive receptions by the general public. As a result, although volatility persisted, Yili's stock price has subsequently showed reversion since November $3^{\text {rd }}$.

\subsubsection{Mengniu}

The melamine incident has caused great negative impact to Mengniu. The company's stock ceased trading for four days after September 17th, and on the day it resumed trading, Mengniu's stock fell about $66 \%$. Mengniu's stock has since gone through a relatively long recovery time, and returned to its pre-incident level only in November 2009. The movement in Mengniu stock prices between 40 days preceding the incident (July 22nd, 2008) to November 12th, 2009 (by which time Mengniu's stock price has roughly returned to its preincident level). For more than one year, Mengniu's stock price reverted back to its normal level before the black swan event.

Mengniu has adopted similar measures to Yili when faced with the black swan event. Both companies engaged in denying wrongdoing and responsibility shirking. They did not admit their own problems, and instead emphasized that they were also victims of the melamine contamination, as the ingredient was added to their products via their suppliers.

From both companies' stock price movements, it can be seen that such measures were rather inappropriate. Relevant government authorities have conducted investigation, and have made clear that both companies' products were contaminated. Given the results of the official investigation, the general public would have developed a confidence crisis towards the involved companies, and the companies must be held accountable for producing defective products. If the involved companies insisted on no wrongdoing and did not face up to the food safety issue, the negative impact would only get even worse.

\subsubsection{Bright}

Following the melamine incident, Bright has promptly adopted measures to manage the crisis, from product quality control to public relation management. From the company's stock price movement, it can be seen that Bright's measures were relatively effective against the black swan event, and its stock price has shown relatively fasters recovery following the incident. The movement in Bright stock prices between 40 days preceding the incident (July 23rd, 2008) to December 10th, 2008 (by which time Bright's stock price has roughly returned to its pre-incident level). For around four months, Bright's stock price reverted back to its normal level before the black swan event.

\subsubsection{Destroying contaminated ingredients and products}

From Bright's 2008 financial reports, it can be seen that general and administrative expenses accounts for $6.4 \%$ of the company's operating profit, an increase of $2.9 \%$ 
from 2007. The main products subject to contamination are a particular sub-brand of baby formula and six batches of liquid milk manufactured by Bright. In order to address the incident, Bright destroyed RMB186 million worth of ingredients and products, affected product lines were shut down, and the company carried out comprehensive monitoring and rectification to its manufacturing plants.

\subsubsection{Apology and compensation}

Three days after the incident broke out (September 19th), Bright's management held a press conference, expressing the company's apology for the food safety incident and stating that Bright will accept all responsibility the incident has caused to consumers, by providing compensation more than those required by national standards, and will take responsibility for all incident related illness. The company also expressed its commitment to make public of the comprehensive investigation conducted by national and local authorities on Bright's full product lines. After the incident, Bright has made timely communication with the media, and became the first source of information to media reporting. The positive image created by Bright of being a responsible enterprise, has played its role in reducing some public concern and loss of confidence in the company.

These measures also brought about the effect of stabilizing Bright's stock price. Bright's stock price was around RMB13 before September 19th, and after the company's press conference the stock price has risen to RMB14.73. Bright's stock price subsequent to the incident was relatively more stable compared to Yili and Mengniu, indicating investor's relative optimism.

Before the incident, Bright has already engaged in a number of charitable activities to build up its responsible company image. For example, from May 2008, Bright has initiated its "cheer for China with love" charitable event, in which the company made donations to more than 70 primary schools across the nation. The company has also played its role in a number of charitable events in 2007, and made a number of disaster relief efforts after the 2008 Wenchuan earthquake, including rescue, donation, and re-building of schools. The series of charitable activities helped Bright to offset some negative impact from the melamine incident.

Apart from effective risk management measures in restoring stock price to its normal level, the magnitude and timing of risk management are also worth investigating. Because Mengniu's financial reports are published half yearly, it is difficult to deduce Mengniu's spending in addressing the black swan event, and the firm's magnitude and timing of risk management. Accordingly, we carry out our analysis only based on Yili and Bright.

\subsection{Firms' risk management magnitude and timing}

Yili and Bright have shown vast difference in term of the magnitude of risk management. Bright has increased its spending on managing the black swan event, with its Q3 spending level significantly greater than the previous quarter, up from Q2's general and administrative expenses growth rate of -0.0254 , to Q3's growth rate of 0.5851 . Yili's Q3 growth rate in 2008 is only 0.0191 , implying that Bright has placed more attention than Yili on the melamine incident and its potential negative impact, with a far greater increase in relevant costs.

In terms of the timing of risk management, while Yili has increased the magnitude of risk management in Q4 2008 compared to Q3 2008, with increase in growth rate being 0.6083, and is similar to Bright's 0.6843, Yili's CARs are still significantly lower than Bright's, indicating less effective restoration effect in Yili's stock price. It can thus be seen that the timing of risk management (first mover vs. followers) will have an effect on firm's restoration process.

\section{Conclusions and recommendations}

\subsection{Conclusion}

In the case analysis of the impact and risk control of melamine incidents on dairy companies, the following conclusions were reached:

(1) The melamine incident has a competitive advantage for non-involved companies in the same industry. It will be able to gain the trust of investors and have an adverse effect on the involved companies.

(2) Controlling the impact of the Black Swan incident is vital to the survival and development of the enterprise. It is necessary to use the correct response strategy to grasp the optimal time for risk handling. If the response to a risk incident is faster, the earlier the processing time is, the risked event will be. The smaller the impact.

(3) At the same time, when an enterprise attaches more importance to the impact of risk events and adopts more effective measures, the greater the intensity of risk treatment, the less the impact of the enterprise stock price on the impact of risk events.

\subsection{Recommendations}

Therefore, the author makes the following suggestions to the enterprise:

(1) Seize the opportunity and deal with risks in a timely manner

After the outbreak of the Black Swan incident, it is necessary to grasp the degree of risk impact with a strategic global vision, predict the risk, and deal with the risk in a timely, effective, reasonable and comprehensive manner. If the crisis management is not enough, it will not only make the involved companies passive when facing risk events, but also lose the best time to control 
the negative impact to the minimum, and eventually lead to consumer and investor brand trust. Risk, the corporate image is seriously damaged.

In the melamine poisoning milk powder incident, Bright, Yili, and Mengniu were also risk-affected companies, but the results of different measures, response levels, and handling efforts of several companies also resulted in different results, with Bright suffering less fluctuations.

(2) Sincerely acknowledge mistakes and actively take social responsibility

When a product safety problem occurs that poses a threat to or impacts on consumers' health and safety, producers must actively assume social responsibility, which is conducive to reducing risks. Through effective communication, explaining the progress of the event to the public, and sincerely admitting mistakes, instead of justifying with excuses and lies, it can reshape the damaged corporate image. In the melamine incident analyzed in this article, the company's (Bright) stocks that actively acknowledged their mistakes recovered quickly, which can reflect this. In addition, in the case of Johnson \& Johnson 's crisis management case in which the Tylenol poisoning incident was handled, Johnson \& Johnson, after discovering that its products have harmed consumers 'bodies, considered it from the perspective of consumers' life and health. Recovered all the millions of bottles of problem medicines distributed, avoided more people being poisoned, and invested \$ 500,000 to inform the relevant doctors and medical institutions. And such rapid and comprehensive crisis management has also made Johnson \& Johnson in the pill poisoning incident, to minimize the adverse impact on corporate reputation damage to a minimum.

(3) Keep in close touch with the media and provide truthful information

The media is the news outlet of the company's related information. The public generally learns about the corporate scandal from the media, and does a good job of media public relations activities, which is conducive for the company to pass the risk. First of all, a press conference should be held at the first time to inform the public of the development of related issues and the remedial measures made by the company, so that the public can understand the truth. On the one hand, it allows the public to see that the company is responsible, not to find various excuses for its own problems, so that the public can also see the measures that companies dare to face and actively assume social responsibility, and regain the trust of the public. On the other hand, disclosure of adverse events such as product quality and safety issues is beneficial to protecting the rights of the public and consumers and preventing more people from continuing to purchase related problematic products, which can minimize risks.

(4) Do a good job in risk aftermath and accumulate experience in crisis management

The aftercare of risk is mainly to deal with and dilute the remaining problems and adverse effects after the occurrence of the risk event. It is necessary to rectify, summarize and draw lessons from the problems that cause risks, properly handle the problems, systematically analyze the causes of risks, summarize the strategies for risk treatment, and accumulate experience for the next time when dealing with risks.

(5) Comprehensively grasp the nature of risk events, and deal with risks reasonably, effectively and effectively

Bright, Yili, and Mengniu have different treatments of risk, and the contrast of the crisis management effect is profound and obvious. Only fully grasping the nature of the risk event, estimating the impact of the risk event, and investing in appropriate processing costs for the risk event can help get rid of the risk as soon as possible, which is the viability of the enterprise.

\section{References}

1. Zhang Zhaozhong, Zhang Ying. Analysis of Food and Drug Recall Shock and Its Influencing Factors Based on Event Research Method [J]. Finance and Economics Series, 2018 (02): 104-112.

2. Liu Mingxia, Meng Xiangjie. Contagion Effect or Competition Effect-Empirical Analysis of Reputation Risk Spillover Effect in Food Manufacturing Industry $[\mathrm{J}]$.Business Research, 2016 (03): 1-9.

3. Zhan Jing Hong, Wu Zheng Zhe. Aviation Incidents and Stock Market Reactions: An Empirical Study of China Airlines in Taiwan [J]. International Journal of Commerce and Strategy, 2012 (4): 41-58.

4. Zhang Kai, Hao Xiaoyan, Wu Laifang. Research on the Impact of "Melamine" Event on the Investment Return of Dairy Listed Companies [J] .Northern Economy, 2010 (04): 63-64.

5. Song Xianzhong, $\mathrm{Hu}$ Yan, Li Sihai. Social Responsibility Information Disclosure and the Risk of Stock Price Collapse__ A Path Analysis Based on Information Effect and Reputation Insurance Effect [J]. Financial Research, 2017 (04): 161-175

6. Tian Gaoliang, Si Yi, Qin Ling, Yu Zhongbo. Public opinion on the Internet and its response and information efficiency of listed companies [J]. Systems Engineering Theory \& Practice, 2018, 38 (01): 46-66

7. Otto Lerbinger, The Crisis Manager: Facing Risk and Responsibility, New Jersey: Lawrence Erlubaum Associates, 1997.

8. Fama E.F, Fisher.L, Jensen M.C, Roll.R. The Adjustment of Stock Price to New Information [J]. International Economic Review, 1969, 10 (1): 1-21. 